Res Publica. Revista de Historia de las Ideas Políticas ISSN-e: 1989-6115

\title{
Alfredo Adolfo Camús y el problema del pauperismo. De los antiguos esclavos a los modernos indigentes*
}

\author{
Josep L. Teodoro Peris**
}

Recibido: 28 de septiembre de 2018 / Aceptado: 10 de junio de 2019

Resumen. Las opiniones sobre el pauperismo de Camús están influenciadas por su conocimiento de la antigüedad clásica, pero sus propuestas siguen la línea del pensamiento social católico que comienza a conformarse en Francia a partir de 1840. Camús es uno de los primeros en exponer en España las ideas de los principales ideólogos de esta corriente.

Palabras clave: pauperismo, esclavitud, servidumbre, literatura clásica, catolicismo social.

\section{[en] Alfredo Adolfo Camus and the Problem of Pauperism. From the Ancient Slaves to the Modern Indigents}

Abstract. Opinions on the pauperism of Camus are influenced by his knowledge of classical antiquity, but his proposals are in the line of Catholic social thought that begins to conform in France from 1840. Camus is among the first scholars in Spain to expose the ideas of the main ideologists of this ideological current.

Keywords: pauperism, slavery, servitude, classical literature, social Catholicism.

Cómo citar: Teodoro Peris, J.L. (2019). Alfredo Adolfo Camús y el problema del pauperismo. De los antiguos esclavos a los modernos indigentes, en Res Publica 22.2, 393-408.

Alfredo Adolfo Camús (1797-1889) accedió a la cátedra de Literatura Griega y Latina en la recién constituida Universidad Central de Madrid en 1846. Esta responsabilidad, que desempeñó durante cuarenta y cuatro años, le convirtió en maestro y referente de toda una generación de brillantes intelectuales que frecuentaron sus clases, entre los que se contaban Pérez Galdós, Clarín, Menéndez Pelayo y Castelar. Con su dinamismo intelectual, introdujo en España autores como Niebuhr, Laromiguière, Buret o Cousin, a la vez que desempeñaba asiduamente el papel de conferenciante en el Ateneo de Madrid, en donde pronunció varias series de conferencias sobre diferentes humanistas españoles y europeos ${ }^{1}$.

* Este trabajo se inscribe en el proyecto de investigación FFI2013-41976, financiado por el MINECO, titulado "Historiografía de la literatura grecolatina en España 3: El legado Alfredo Adolfo Camús en la Biblioteca Histórica Marqués de Valdecilla", dirigido por Francisco García Jurado.

** Universitat de València josep.1.teodoro@uv.es

1 Para el encuadre histórico y académico de Camús, cf. la monografía de F. García Jurado, Alfredo Adolfo Camús (1797-1889). Humanismo en el Madrid del siglo XIX, Madrid, Ediciones Clásicas, 2002. 
Su profundo conocimiento de la antigüedad clásica, su gusto por la historia y una cierta amplitud de miras hacia las corrientes contemporáneas de pensamiento le permitieron elaborar una síntesis filosófica muy personal, que impregnó su docencia y su actividad pública. Así se pone también de manifiesto en su opinión sobre el problema de pauperismo, fenómeno relacionado con la creación de una moderna clase obrera urbana y con la implantación en nuestro país de las reformas capitalistas promovidas por la revolución industrial.

El doce de mayo de 1847, bajo la presidencia de Antonio Alcalá Galiano², Camús leyó en el Ateneo de Madrid una conferencia "respecto de la beneficencia pública, cuáles son los derechos de los pobres y las obligaciones de la sociedad, y qué disposiciones se pueden adoptar para suavizar los males de la desigualdad de fortunas sin atacar la propiedad (Camús 1847: 1)"”, que respondía a un acuciante problema social sobre el cual el Estado aún no había tomado disposiciones apropiadas a la gravedad de la situación. Los socorros privados, limitados a la caridad organizada a través de las instituciones religiosas, eran escasos y carecían de la uniformidad y la extensión necesarias para subvenir a las necesidades de un proletariado que sufría duramente las consecuencias de las desamortizaciones y la progresiva mecanización de las manufacturas. La lenta penetración en España de la concepción del Estado como garante del bienestar público trajo consigo la idea de organizar los necesarios socorros a cuenta de la administración pública, un proceso que vio diversas tentativas legislativas, no siempre concluidas con éxito.

Cuando Camús pronunció la conferencia que nos ocupa, las diversas posiciones políticas mantenían puntos de vista claramente diferentes respecto a la beneficencia. El tradicionalismo político y religioso, agrupado en torno al carlismo, daba por bueno el mantenimiento de las estructuras del Antiguo Régimen, con una beneficencia gestionada por la Iglesia y ligada a la caridad privada, que debía sustentarse con las rentas de las propiedades eclesiásticas y monásticas. Los sucesivos procesos de desamortización ${ }^{4}$ de los bienes que se encontraban en poder de las llamadas "manos muertas", que tenían el propósito de aliviar con su venta la ingente deuda pública, habían reducido considerablemente el patrimonio y la autonomía financiera de las instituciones caritativas religiosas.

2 Alcalá Galiano había evolucionado en ese momento hacia unas posiciones políticas que defendían, dentro de un sistema constitucionalista, la importancia de la tradición y de la religión como elemento vertebrador de la sociedad y del progreso tecnológico, en línea con el pensamiento de Edward Burke, como tantos otros católicos preocupados por el malestar social que producía la implantación de la nueva economía capitalista industrial. En este sentido, veremos que se encuentra muy próximo al pensamiento de Camús. R. Sánchez García, Alcalá Galiano y el liberalismo español. Madrid, Centro de Estudios Políticos y Constitucionales, 2005.

3 Discurso conservado en el AGA: IDD (05)001.019 (Expedientes personales de docentes universitarios 18501923), caja 31/15466, exp. 253-40. Expediente personal de Alfredo Adolfo Camús y Cardero. El documento carece de título y está fechado en la última hoja en Madrid el 12 de mayo de 1847 . Nuestras citas se realizarán sobre este documento y sobre su paginación original, manteniendo la ortografía del autor. Para el resto de referencias en el artículo emplearemos únicamente la fecha del documento.

4 Las desamortizaciones parciales de propiedades comunales y eclesiásticas se sucedieron durante todo el s. XIX, durante los gobiernos de Godoy (1798), de José Bonaparte (1808-1813), de las Cortes de Cádiz (1810-1814), del Trienio Liberal (1820-1823), hasta llegar a la mucho más completa bajo la dirección de Juan Álvarez Mendizábal (1836-1837), proseguida bajo Espartero (1841) y concluida por Madoz (1854-1856), que fue, con mucho, la más profunda. Cf. F. Tomás y Valiente, J. Donézar, G. Rueda, J. M. Moro, “La desamortización”, Cuadernos historia $16, \mathrm{n}^{\circ} 8,1985$. 
Los conservadores en lo político y en lo social, pero opuestos a la estructura política del Antiguo Régimen, agrupados en el Partido Moderado, entendían que la Iglesia debía mantener la iniciativa en el auxilio a los necesitados, con la colaboración subsidiaria de la administración pública. Este es el sentido del Reglamento General de Beneficencia que se aprobó en 1821 durante el Trienio Liberal, y que fue restablecido y revisado a raíz del pronunciamiento de La Granja de 1836 por voluntad del nuevo Secretario de Estado de Fomento, Javier de Burgos. En él se ordena que en cada ayuntamiento se constituya una Junta de Beneficencia presidida por el alcalde y compuesta - en las grandes localidades - por este, el cura párroco más antiguo, un regidor del ayuntamiento, un médico y tres vecinos "de los más pudientes e ilustrados" , mandando que "en las poblaciones de mucho vecindario", se formen unas "Juntas Parroquiales de Beneficencia, que serán presididas por el Cura de la parroquia" $"$.

La burguesía más dispuesta al cambio, que tenía como referente el Partido Progresista y como cabezas visibles a Salustiano de Olázaga y a Baldomero Espartero, presentaba un espectro ideológico más amplio: si bien la mayoría estaba a favor de un sufragio censitario que restringiera el acceso al voto de la clase obrera, una pequeña parte, que luego constituyó el Partido Demócrata, sostuvo a partir de la década de 1840 la implantación del sufragio universal. Había sin embargo un mayor consenso en reducir la presencia social de la Iglesia, que daba lugar a numerosas declaraciones anticlericales.

En lo tocante a la beneficencia, los progresistas eran partidarios de la organización de un sistema de ayudas organizado por el Estado y sustentado a través de la iniciativa privada y la inversión pública, iniciando el debate sobre la instauración de una tasa para financiar las instituciones de caridad, según el modelo inglés.

Al mismo tiempo, fuera del sistema constitucional, se estaba formando una nueva opción política a partir del naciente movimiento obrero, que veía en la alternancia de partidos constitucionalistas y en el sufragio censitario un impedimento insalvable para el cambio social. Esta nueva dinámica política, circunscrita inicialmente al proletariado urbano, cristalizó durante la década de 1830-40 en la fundación de numerosas "sociedades de socorros" . La función de estas entidades, eminentemente pragmáticas, era mejorar las condiciones de vida del obrero a través de la creación de cooperativas laborales y de consumo y del establecimiento de una red de asistencia mutua, que intentaba suplir las carencias de la beneficencia pública y, al mismo tiempo, alejarse de la dependencia de las instituciones eclesiásticas.

En este contexto, esbozado a grandes rasgos, Camús expone sus ideas sobre el derecho de los pobres a recibir asistencia y socorro, y las obligaciones de la sociedad hacia los más desfavorecidos. Es de notar la prudencia de Camús a la hora de plantear aspectos como la creación de un impuesto para sufragar la ayuda social, y aun es más relevante el posicionamiento de nuestro autor en un difícil equilibrio entre el tradicionalismo católico y el liberalismo moderado, una posición política con pocos referentes en nuestro país y con poco desarrollo posterior.

\footnotetext{
$5 \quad$ Reglamento general de beneficencia pública decretado por las Cortes Estraordianarias de 1821, sancionado en 6 de Febrero de 1822 y que mandado establecer por S. M. fué publicado por el Sr. Gefe Superior político de la Provincia por medio del Boletín Oficial en octubre de 1836. Barcelona, Imprenta de Gaspar, 1837. p. 4. Ibidem p. 6.

M. Tuñón de Lara, El movimiento obrero en la historia de España. I. 1832-1899, 1977 (2ª edición 1972), Barcelona, Laia, p. 41.
} 
La cuestión social había estado presente en ese mismo foro algunos años antes, en 1840, cuando Ramón de la Sagra había expuesto unas Lecciones de economía social en las que contestaba las opiniones que el asturiano Álvaro Flórez Estrada había plasmado en su opúsculo La cuestión social, o sea, origen, latitud y efectos del derecho de propiedad (1839). Flórez proponía — en franca oposición a la política de desamortización y subasta - el arriendo enfitéutico a los campesinos sin tierra de las grandes propiedades de manos muertas ${ }^{8}$, lo que fue contestado como un ataque al sagrado derecho a la propiedad. Los propios términos del debate, recogidos por los títulos de las diferentes obras traídas a colación, denotan que ya en 1840 la discusión sobre el pauperismo había superado los conceptos de beneficencia y caridad para situarse en un enfoque mucho más amplio, que buscaba soluciones a la extensión de la pobreza a partir de una completa reorganización social. La misma orientación se detecta en los trabajos presentados en la Sociedad Matritense de Amigos del País, que en 1845, un par de años antes del discurso de Camús que nos ocupa, había convocado un premio al mejor estudio sobre los medios para erradicar el pauperismo. Las memorias vencedoras planteaban conceptos como la organización del trabajo, la equidad en el reparto del producto o la asociación productiva ${ }^{9}$, nociones que no aparecen en el discurso de nuestro erudito profesor.

El primer argumento que expone Camús es que la pobreza no es un fenómeno propio de las circunstancias sociales del momento, sino que ha existido siempre en mayor o menor medida. La fuente de su reflexión, como él mismo confiesa, es Antoine-Eugène Buret, economista y sociólogo francés, autor de La misère des classes laborieuses en France et en Angleterre (1840), una de las primeras contribuciones al debate sobre el pauperismo, que se adelantó cuatro años a la obra sobre el mismo argumento de Friedrich Engels. La obra de Buret sirvió de base para las reflexiones de Proudhon y de Marx, pero tiene un tono mucho menos reivindicativo de lo que haría suponer esta influencia posterior. El pensamiento de este autor se encuadra en la nueva línea de la Academia de Ciencias Morales y Políticas de París, refundada en 1832 por los llamados doctrinarios, es decir, aquellos que sostenían la Carta Otorgada de 1814 y una línea política intermedia entre el absolutismo y el constitucionalismo del periodo revolucionario. Sus ideas sociales pasaban por el refuerzo de la clase media y la implicación de los intelectuales en la defensa del régimen de la Restauración, y sus criterios filosóficos estaban dominados por el eclecticismo de Victor Cousin - muy presente en la biblioteca personal de Camús - y otras figuras como Charles Remusat o Théodore Jouffroy ${ }^{10}$.

Buret sitúa el origen de la pobreza en la propia constitución humana. El hombre es el animal menos preparado por naturaleza para alimentarse y encontrar cobijo. $\mathrm{Su}$ sensibilidad y la delicadeza de sus órganos aumentan sus necesidades materiales. Y ni siquiera una vez satisfechas estas el hombre puede encontrar reposo, porque otras necesidades espirituales, tan imperativas como las primeras, le llevan a nuevos trabajos y a experimentar otras miserias ${ }^{11}$. En palabras de Buret, "la pauvreté, dans son sens absolu, est la condition naturelle de l'humanité", y las necesidades humanas

\footnotetext{
$8 \quad$ G. Capellán de Miguel, "Cambio conceptual y cambio histórico. Del pauperismo a la cuestión social”, en Historia contemporánea 29, 2005, p. 563.

$9 \quad$ Ibidem, p. 569.

$10 \quad$ Ibidem, p. 550.

11 A.-E. Buret, La misère des classes laborieuses en France et en Angleterre, 2 ed. 1840, p. 103.
} 
superan los medios para satisfacerlas. La idea, muy extendida en el pensamiento político de la era preindustrial, de que la pobreza es una condición general y la riqueza una rara anomalía, está en el origen tanto de la justificación de la beneficencia en cuanto acto de restitución a la comunidad del exceso que la suerte ha deparado al rico, como de leyes que limiten el enriquecimiento o que propongan la redistribución del exceso de bienes de los ricos entre los desposeídos. Se trata de una idea de raíces clásicas, que tiene su base en las limitaciones de la economía de subsistencia de la edad preindustrial, y que es duramente combatida por el liberalismo ortodoxo.

Para situar el debate en un contexto histórico, Camús traduce un amplio fragmento de la obra de Buret ${ }^{12}$, que pone de manifiesto hasta qué punto las sociedades antiguas consideraban el trabajo manual una actividad degradante. Como prueba de ello, Buret incluye un fragmento del Económico de Jenofonte ${ }^{13}$, en el que se afirma que el trabajo manual no solo produce un rápido deterioro físico, sino también el embotamiento de las facultades del alma. Esta idea ha persistido en la civilización europea con tal arraigo que, hasta "la generación que nos ha precedido", el trabajo era considerado un deshonor y "la ignorancia, un signo de hidalguía" (1847: 6).

A los ojos de Camús ni siquiera "los mártires de la industria"14 (1847: 6) caídos en las recientes transformaciones económicas han logrado cambiar esta nota infamante que acompaña el trabajo manual y mecánico; solo la agricultura ha sido considerada una ocupación honrosa, pues era ejercida en la antigüedad por hombres libres, y no por esclavos, que se ocupaban principalmente, de las tareas industriales y domésticas ${ }^{15}$.

Buret - y Camús con él - no tiene en cuenta que, en Jenofonte (Econ. 6, 9), la agricultura no es considerada una ocupación degradante en la medida en que permite disponer de tiempo para la actividad política, que es la marca distintiva del ciudadano libre. En la polis anterior a la expansión de Roma y de la economía esclavista a gran escala por el Mediterráneo, la condición servil, además de ser una marca económica dentro del sistema de producción, es una circunstancia que opone la condición de ciudadano activo a la de miembro pasivo de la comunidad. En este sentido, mujeres y esclavos, relegados de la vida política, aparecen en Aristóteles (Pol. 1252b) como seres que comparten por naturaleza la condición de obedecer.

Más que la condición servil, es la pobreza en sí misma la que marca al individuo que la sufre con el estigma de una baja estima social, como se puede ver en la correlación moral que establece la literatura antigua desde Homero entre nobleza de cuna

12 Camús incorpora a su redacción una buena parte del capítulo segundo del libro tercero de Buret. En total, en el discurso de nuestro autor la cita ocupa seis cuartillas (de la 4 a la 10) de un total de 18. Cf. A.-E. Buret, op. cit. vol. 2. p. 67-72.

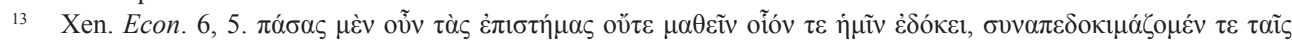

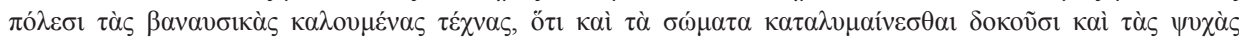
$\kappa \alpha \tau \alpha \gamma v$ ovø. La misma opinión ibidem 4, 2-3, fragmento que no cita Camús porque no aparece en Buret.

14 La expresión, acuñada por Buret y reproducida por Camús, hizo fortuna en el lenguaje político español, y la volvemos a encontrar en Emilio Castelar, alumno de Camús en la Universidad Central: "Sería cruel negar la existencia de un problema social, cuando está escrito a nuestros mismos ojos en la tierra que pisamos, con las lágrimas de tantos desgraciados y con la sangre de tantos mártires [...]”. Cf. M. Artola, Partidos y programas políticos 1808-1936. Tomo II. Manifiestos y programas políticos, Madrid, Alianza Editorial, 1991, p. 75. Sobre la relación entre Camús y Castelar, cf. A. A. Camús, Carta a don Emilio Castelar. Edición y estudio introductorio de María José Barrios y Francisco García Jurado, Escolar y Mayo Editores, Madrid, 2015, pp. 15-90.

15 Sobre la obra historiográfica de Camús, cf. M. Romero Recio, "Historiografía de la España Antigua en la España del siglo XIX: Alfredo Adolfo Camús y los historiadores”, Entre dos mundos: Homenaje a Pedro Barceló, Presses universitaires de Franche-Comté, 2017, pp. 687-710. 
y riqueza con nobleza de ánimo e incluso con belleza física. Paradigmas de esta concepción son el caso del Tersites homérico (Ilíad. 2, 212-277) — personaje que, significativamente, es analizado de modo muy diferente por la crítica literaria marxista contemporánea ${ }^{16}$ - y el empleo en la comedia grecolatina del personaje del pobre, del esclavo o del parásito como contrapunto cómico, interesado o mezquino en relación con los personajes de clase alta, que representan valores morales más elevados.

Ligar el derecho de actuación política a la propiedad y negarlo a la pobreza es una constante en el mundo antiguo, que volvemos a encontrar en el momento en que se recupera el concepto de ciudadano en la cultura occidental, con la implantación del sufragio censitario. En la historia del constitucionalismo español, importante para entender los términos en los que se mueve Camús, habrá que esperar hasta la Constitución de 1869 para ver legalizado el sufragio universal masculino. En 1847, momento de la redacción del discurso que nos ocupa, la promulgación de la Constitución de 1845 ha restringido el derecho de sufragio con respecto a la anterior ley fundamental de 1837, creando un Senado nombrado enteramente por la Corona y unos ayuntamientos en los que el Alcalde también depende del nombramiento real, y no del voto - restringido y censitario- de los vecinos varones.

En la discusión sobre el sufragio universal del s. XIX se unen dos conceptos que tienen su origen en la antigüedad: por una parte, la identificación de ciudadano activo con propietario y hombre libre, que dispone del tiempo necesario para dedicarse a los asuntos políticos porque el trabajo servil lo libera de la obligación de ganarse el sustento; por otro lado, la naturaleza imperfecta del esclavo que lo hace únicamente partícipe de una inteligencia limitada y que se suma al embrutecimiento que provoca el trabajo manual (Arist. Pol. 1337b). El trabajo industrial moderno, en este sentido, solo ha hecho que aumentar aún más la alienación del obrero, obligado a tareas repetitivas y monótonas que convierten al hombre, según Marx y Engels, en "simple resorte de la máquina"17. De ahí la insistencia de las asociaciones obreras en mejorar las condiciones no solo económicas, sino culturales y morales del proletariado, como único camino para garantizarle una vida cívica de relevancia política. Por su parte, los estudiosos de la cuestión obrera desde la esfera del cristianismo, no dejan de insistir sobre la necesidad de ampliar la educación — sobre todo moral— del proletariado, por lo que sorprende que Camús no haga referencia alguna en su discurso a las necesidades formativas de los desposeídos.

Los autores que Camús reconoce haber consultado para la redacción de su discurso, consideran relevante el problema de la educación del obrero. El barón de Gérando, en su tratado De la bienfaisance publique de 1838, considera que hay una relación directa entre la instrucción y la cantidad de proletarios ${ }^{18}$; pero sin duda, quien mejor expone el alcance de la cuestión es Villeneuve-Bargemont, que dedica un capítulo entero de su Économie politique a disertar "De l'ignorance et de l'immoralité dans les classes inférieures"19, confrontando las "écoles du peuple" tal como

16 B. Jessop y R. Wheatley, Karl Marx's Social and Political Thought, Critical assessments of leading political philosophers, vol. 5, Taylor \& Francis Ed., 1999, p. 137.

17 K. Marx y F. Engels, Manifiesto del Partido Comunista, Fundación de Investigaciones Marxistas, Wenceslao Roces, trad. 2013, p. 58

18 J. M. Gérando, De la bienfaisance publique, 1838, p. 113: "L'instruction est un vrai capital ; elle est un moyen d'exploitation, elle représente des avances faites. De là, un rapport inevitable entre le règne de l'ignorance et le nombre des prolétaires".

19 A. Villeneuve-Bargemont, Économie politique chrétienne ou recherches sur la nature et les causes du paupe- 
las conciben los ingleses, con la "école chrétienne" que él plantea como modelo educativo del proletariado. Una formación exclusivamente práctica, basada en el dominio de la lectura y de la escritura y en los conocimientos necesarios para manipular la maquinaria fabril no es, a juicio de Villeneuve-Bargemont, una instrucción adecuada para el obrero. Sin una sólida educación moral, se verá abocado rápidamente a la disipación y el vicio, a la imprevisión y a la miseria. En cambio, el obrero religioso,

par vertu, plus encore que par intérêt, sera l'ami du travail, de l'ordre, de la frugalité. Accomplir ses devoirs de fils, d'époux, de père, de citoyen, de chrétien sera le but auquel il tendra sans cesse. C'est pour l'atteindre qu'il cherchera à développer son intelligence, à conserver ses forces, a acquérir de l'habilité, à faire des épargnes. Plein de respect pour lui-même comme pour les autres, il sera avide d'une bonne renommée, car il saura très bien que l'estime et la confiance se donnent plutôt à la probité qu'à l'habilité sans vertus. Si ses travaux prospèrent, il s'élèvera avec joie à un degré de plus dans l'échelle sociale ; s'ils le laissent dans la médiocrité, dans l'indigence même, il ne murmurera point, car il saura aussi que cette vie passagère n'est qu'une épreuve et que "les pauvres entrent plus aisément au royaume éternel que les riches dont la récompense est en ce monde"20.

La formación religiosa actúa no solo como garante de la moral y de las buenas costumbres que impiden la caída del obrero en la miseria, sino también como muro de contención contra las veleidades revolucionarias. El cristianismo social, en un primer momento, se preocupa sobre todo de garantizar la formación religiosa del proletariado, prestando menos atención a la instrucción académica y a la formación política ${ }^{21}$. La armonía social, el objetivo final, se alcanza mediante el ejercicio perfecto de las virtudes cristianas. Quizá por ello Camús no parece detectar en su discurso un problema en la falta de instrucción del obrero. En nuestro país hay que esperar hasta el último tercio del siglo XIX para ver articulada en los círculos burgueses una propuesta que incluya la instrucción del proletariado como elemento de solución del problema social. La conocida fórmula "escuela y despensa" de Joaquín Costa forma parte de una línea que recoge plenamente la voluntad regeneracionista que tomó impulso definitivo con la crisis de 1898 y que tuvo su máximo exponente en la Institución Libre de Enseñanza.

No conocemos la opinión de Camús sobre la presencia de los principios religiosos en la educación primaria. Su posición, sin duda favorable si atendemos a sus muestras de respeto a "los sagrados preceptos del cristianismo (1847: 11)", debía ser bastante matizada, como indica su defensa de los estudios clásicos ante el ataque de los neocatólicos como consecuencia de la publicación en 1851 de Le ver rongeur des sociétés modernes ou le paganisme dans l'éducation de Jean-Joseph Gaume ${ }^{22}$. Así lo indica, también, el "perfil bajo" que mantuvo en la pugna por el predominio ideológico entre neocatólicos y krausistas que estalló en 1857, año de la aprobación de la Ley de Instrucción Pública, con la lección de apertura del curso universitario de

risme en France et en Europe et sur les moyens de le soulager et le prevenir. Tome 1, Paris, Paulin, 1834, pp. 479-494.

20 A. Villeneuve-Bargemont, op. cit. pp. 483-484.

21 El barón de Gérando, sin embargo, dedica una amplia sección de su obra a la educación de los indigentes. Gérando, op. cit. p. 440-497.

22 F. García Jurado, op. cit. p. 67. 
Julián Sanz del Río, en la que este demandó que la ciencia y la educación se liberasen de la tutela ejercida tradicionalmente por el Estado y la Iglesia ${ }^{23}$.

La exposición de Buret — que Camús continúa traduciendo en su discursopone de manifiesto una contradicción del pensamiento contemporáneo: aunque la economía moderna vea en el trabajo la fuente de toda riqueza y la filosofía lo considere el "manantial de todos los derechos" (1847: 7), la sociedad no ha acabado de digerir estos nuevos principios, desde el momento en que el trabajo conserva la lacra infamante del pasado. El esclavo del hombre de la Edad Antigua pasó a ser esclavo de la tierra en la Edad Media, para convertirse en la Edad Contemporánea en esclavo de las necesidades del cuerpo, que lo obligan a agotar su fuerza de trabajo en fatigas tan penosas como las de los esclavos antiguos, pero más mudables, porque dependen "las vicisitudes de la industria, que puede mañana por un capricho de la moda negarle el triste alimento que le hubiera proporcionado ayer (1847: 7-8)".

Para Camús, el origen del pauperismo es, precisamente, el desamparo en que el trabajador manual y el campesino han quedado con la abolición de la esclavitud y, más tarde, con la abolición de la servidumbre, que vinculaba moralmente al señor con el vasallo ${ }^{24}$.

En efecto, la literatura antigua presenta numerosos ejemplos del vínculo afectivo que se establecía entre el amo y el esclavo, y el Manual de antigüedades romanas de Ozaneaux ${ }^{25}$, que Camús en este punto traduce sin cambios, insiste en esta visión parcial y hasta cierto punto tolerante de la esclavitud. Ni la extensión ni el propósito de manuales de este tipo, pensados para proporcionar textos de estudio condensados y generalistas, permiten hacer un estudio en profundidad de la evolución del modo de producción esclavista en el Imperio Romano, pero es evidente que el desarrollo económico de los siglos II y I AEC transformó el trabajo servil en medida comparable a la manera en que la revolución industrial de los siglos XVIII y XIX cambió el trabajo libre asalariado.

El paso de la esclavitud patriarcal, en donde el erus es dueño de todas las vidas y propiedades de la familia, y ejerce una potestas de naturaleza semejante sobre su esposa, y sobre sus hijos "liberi" y sus esclavos "servi", que son considerados como fuerza de trabajo común, a un nuevo tipo de esclavitud masiva y despersonalizada está perfectamente consignado en la legislación romana. La Ley de las XII Tablas, del s. V AEC, condena a quien causa la fractura de un miembro a pagar una indemnización al herido, ya sea libre o esclavo, con la única diferencia en el caso de la persona libre de que la indemnización es doble que si se trata de un esclavo. Con todo, la ley reconoce la iniuria contra la persona en ambos casos, independientemente de la condición civil del afectado ${ }^{26}$. Pero cuando la esclavitud patriarcal cede su

23 G. Capellán de Miguel, "Política educativa bajo los gobiernos de Cánovas y Sagasta: Propuestas para una interpretación”, Berceo 139, Logroño, 2000, p. 125.

24 La misma idea se encuentra en el barón de Gérando, op. cit., p. 83.: "Les époques d'abolition de la servitude et de la féodalité ont été marquées par l'apparition d'una classe nouvelle et nombreuse de miserables, qui, ne pouvant se souffire à eux-mêmes, invocaient les secours publics, et souvent menaçaient l'ordre social lui-même, en demandant à la violence les ressources qu'ils ne savaient ou ne pouvaient réclamer par l'industrie".

25 G. Ozaneaux, Les Romains. Tableau des institutions politiques, religieuses et sociales de la Republique Romai$n e$, Paris, Guyot et Scribe, 1840. La traducción de Camús lleva por título Manual de antigüedades romanas, ó cuadro abreviado de las instituciones políticas, sociales y religiosas de Roma, por M. G. Ozaneaux, traducido y anotado por Alfredo Adolfo Camús. Madrid, Boix, 1845.

26 Y. Thébert, "Lo schiavo", Andrea Giardina ed., L'uomo romano, Editori Laterza, 2003, p. 159. 
puesto a la nueva economía esclavista a gran escala, la situación del seruus cambia radicalmente. La lex Aquilia de finales del s. III AEC considera que la herida a un esclavo no es un daño a su persona, sino un perjuicio al patrimonio de su dueño, que recibe una compensación. La palabra erus, en este nuevo contexto, queda relegada al ámbito poético y deja paso a dominus ${ }^{27}$, que recoge con mayor precisión la nueva dimensión de la relación entre el dueño y el esclavo, convertido en una maquinaria humana empleada profusamente en las grandes plantaciones y en las manufacturas, donde desempeña un trabajo mecánico y limitado a unos pocos movimientos especializados, muy semejante al que se implantará siglos después en las cadenas de montaje de la industria.

A medida que la estructura social se hace más compleja, el dominus cede al Estado aspectos del control absoluto que ejercía sobre sus esclavos, del mismo modo que pierde también poder en la autoridad que ejercía sobre su esposa y sus hijos ${ }^{28}$.

El paulatino reforzamiento del poder del emperador, convertido en pater patriae, le arroga un nuevo poder al interno de las familias como árbitro del conflicto entre dominus y servus. Claudio prohíbe la muerte de un esclavo incapaz de trabajar; Adriano concede la libertad a los esclavos abandonados por enfermedad. El dominus puede permitirse ser más benigno porque al mismo tiempo las leyes garantizan y responden de su seguridad, y el Estado adquiere un papel represivo que solo había tenido antiguamente el propietario ${ }^{29}$. Camús no observa en su exposición el paralelismo que existe en la evolución del sistema esclavista y el desarrollo de la moderna clase obrera. El aumento de esta última obliga al Estado a intervenir del mismo modo que lo hizo la legislación de época imperial: por un lado, reconociendo derechos a los trabajadores para limitar los abusos patronales y reducir el malestar social; por otro lado, defendiendo directamente los intereses de los propietarios en caso de huelgas y motines, cosa que no había sido necesaria hasta ese momento y que acaba de completar el paso del Estado a mediador necesario entre patrón y trabajador.

Insistiendo en este punto de su exposición, Camús reproduce el largo párrafo de Sir Frederick Morton Eden (1766-1809) que también Buret incluye en su obra, para poner de manifiesto el vínculo de dependencia mutua que se establecía en la Edad Media entre señor y vasallo, que a su juicio evitaba la situación de desamparo a la que se ve abocado el actual obrero sin recursos:

En tiempos de calamidad [...] un gran propietario de tierras se veía muchas veces tan apurado para dar de comer á las bocas hambrientas que lo cercaban, como un obrero libre lo estaba para sustentarse á sí propio; y la hambre, á no dudarlo, se hacía tan cruelmente sentir al dueño de una heredad como al manufacturero (Camús, 1847: 10) $)^{30}$.

\footnotetext{
Ibidem p. 161.

Ibidem p. 163.

Ibidem, p. 173.

A.-E. Buret, op. cit. p. 70, citando a F. Morton Eden, The State of the Poor, or An History or the Labouring Classes in England, from the Conquest to the Present Period, vol. 2, 1797. La idea es recurrente en este autor. Cf. F. Morton Eden, op. cit., vol. 1, 1797 (2011), p. 11: "The state of the vassalage, in those feudal times, which are sometimes, perhaps, somewhat too summarily reprobated, would not have been so unpropitious to the individual happiness of any member of the community".
} 
De este modo, para nuestro autor la miseria es doblemente inevitable: por un lado, es el estado natural del ser humano, del que son excepción los pocos ricos, irrelevantes en el conjunto de la pobreza humana. Por otra parte, el cambio de modelo productivo, con la transformación del trabajo servil y feudal en trabajo asalariado, ha roto los lazos que podrían asegurar el bienestar del obrero. Además, Camús no parece confiar en las posibilidades de la sociedad para recuperar esa situación armónica que cree ver en el pasado, ni siquiera bajo la influencia del cristianismo, porque considera imposible acabar con este estado de cosas "á no ser que con peligro de derribar el edificio entero, nos dejemos abrazar por la tentación de engolfarnos en los poéticos sueños de Platón, Fourrier ó de Saint-Simon (1847:10)". Queda claro que, para Camús, la única posibilidad real no es cambiar la distribución de la riqueza o el tipo de relación social, sino aliviar la situación de aquellos que padecen la miseria.

Buret, en su exposición, distingue atentamente entre la situación del trabajador industrial - cuyo estado considera peor que el del antiguo siervo de la gleba-, del contexto en el que se halla el campesino en Francia, que ha accedido a la posesión de la tierra de manera mayoritaria y que, participando en "la propriété de l'instrument de travail", se encuentra doblemente interesado en aumentar la producción ${ }^{31}$. Camús, que en este apartado de su discurso sigue a Buret de cerca, no parece caer en la cuenta de que la situación española es harto diferente, porque en nuestro país el problema del pauperismo es eminentemente rural, y los jornaleros y braceros sin recursos son mucho más numerosos que los trabajadores industriales en situación de pobreza. Deja, pues, este aspecto sin analizar, olvidando que no faltaban en nuestro país voces autorizadas en este enfoque del pauperismo, desde el momento en que la cuestión agraria había sido tema recurrente en la preocupación de los ilustrados de finales del siglo XVIII ${ }^{32}$.

Una vez establecido el carácter inevitable y eterno de la pobreza, y después de haber renunciado a cualquier intento de encarar la solución del problema mediante reformas sociales que pongan en discusión principios tales como el derecho a la propiedad y a la herencia, nuestro autor centra la cuestión en el análisis de las medidas que se pueden tomar para paliar el estado de necesidad extrema de una amplio segmento de la sociedad.

La primera pregunta que plantea a su auditorio es si el deber de beneficencia atañe a la justicia social o a la caridad. Hasta ese momento, el socorro al necesitado ha sido entendido como un deber de conciencia, recogido por la moral cristiana, y reducido al ámbito de la caridad, pero las condiciones actuales y el alcance del problema parecen demandar soluciones que impliquen a toda la sociedad en su conjunto.

Para dar respuesta a esta cuestión, Camús emplea una larga cita de Louis-Firmin Laferrière $^{33}$. En ella, el también miembro de la Académie des sciences morales et politiques declara que considerar la asistencia a los pobres como un derecho de justicia, implica reconocer que existe una deuda social hacia ellos que debe ser pagada mediante una participación de los bienes de los otros miembros más pudientes de la sociedad. Esto supone socavar el indiscutible derecho a la propiedad. Desde el momento en que el Estado se arroga la potestad de detraer obligatoriamente una

A.-E. Buret, op. cit. pp. 72-73.

G. Capellán de Miguel, op. cit. p. 563.

L.-F. Laferrière, Cours de droit public et administratif, par M. F. Laferrière, ancien professeur de droit administratif à la faculté de Rennes. Deuxième édition, Paris, Jouvert, 1841-1846, pp. 322-323. 
parte de la fortuna, aunque sea mínima, de los miembros con mayores recursos de la sociedad, está poniendo en discusión el principio fundamental del liberalismo, que es el derecho absoluto y sagrado a la propiedad. Camús considera esta idea "una falsa nocion que llevada hasta sus últimas consecuencias, arrastraria en pos de sí el espíritu de la perturbacion y la ley agraria" (1847: 12), es decir, llevaría a plantear una ley de reforma agraria y de reparto de latifundios que iría contra el espíritu del liberalismo económico que impulsaba el proceso de desamortización aún vigente. Resulta interesante comprobar que la única referencia que Camús hace a una de las pocas figuras de la Antigüedad que lucharon por mejorar las condiciones de los desposeídos, Tiberio Graco ${ }^{34}$, sea para ponerlo en relación con los disturbios que se produjeron al final de la Republica Romana. Aunque el peligro no parece inminente, Camús considera prudente alertar contra las consecuencias que las propuestas más innovadoras en este campo — como sería la de Álvarez Flórez, ya comentada — pueden acarrear para el orden social, e incluso contra la implementación de una simple tasa sobre los predios o bienes inmuebles.

En definitiva, nos hallamos ante dos concepciones que se oponen claramente en el debate político del momento. Por un lado, el Estado liberal, voluntariamente limitado, que no interviene en economía excepto para dirimir los conflictos entre las partes enfrentadas, y que solamente garantiza el ejercicio de la libertad individual en lo tocante a la propiedad, sin contemplar derechos colectivos. El Estado liberal, por oposición al Antiguo Régimen, se define como un Estado de derecho que garantiza la igualdad jurídica y la movilidad social a través del éxito del esfuerzo personal en el trabajo. En la práctica, la ausencia de derechos colectivos - y la desconfianza de las instituciones del Estado hacia aquellas instituciones privadas que pretenden ampliarlos, como sociedades de ayudas mutuas laborales-, deja en posición de desvalimiento a los elementos más débiles, como son los obreros y los campesinos, aumentando el malestar social. Pasamos por alto, sin embargo, que el liberalismo económico incurre en el momento del que hablamos en flagrantes contradicciones, como son las repetidas desamortizaciones, venta obligatoria de propiedades colectivas o de "manos muertas", es decir, con bajo nivel de inversión y productividad, que no dejan de ser - y así son denunciados por los sectores más tradicionalistasataques a la inviolabilidad de la propiedad privada.

Por otro lado nos encontramos con las primeras líneas definitorias de otro concepto de Estado, el llamado Estado social ${ }^{35}$, que se desarrolla como alternativa burguesa al liberalismo, y cuya definición parte desde dos fuentes aparentemente contrapuestas, como son la tradición cristiana - que tiende a ver la sociedad como un cuerpo de intereses complementarios unido por una voluntad moral de mejora-, y la defensa de los derechos de los trabajadores, que empieza a dar forma al nuevo concepto de lucha de clases. De hecho, el reconocimiento de los peligros de esta lucha de clases, y la idea de que el empobrecimiento excesivo de las clases bajas solo puede llevar a la descomposición del Estado y, en último término, a una indeseable revolución social, estimulan desde los centros del poder político de matriz cristiana la construcción este nuevo concepto de Estado protector que debe garantizar al ciu-

\footnotetext{
Plut. Tib. 9.
}

35 Se reconoce como impulsor de este concepto a Lorenz von Stein $(1815$ - 1890) y a sus observaciones sobre el movimiento obrero francés plasmadas en Der Sozialismus und Kommunismus des heutigen Frankreich (Leipzig 1842) y en Geschichte der sozialen Bewegung in Frankreich von 1789 bis auf unsre Tage (Leipzig 1850). 
dadano la obtención de los poderes públicos de todo aquello que siéndole necesario para subsistir dignamente quede fuera de su alcance por sus propios medios.

Sin renegar del liberalismo económico, cuyo ideario mantiene en su mayor parte, el Estado social cristiano es intervencionista en economía, pero opuesto a soluciones socialistas o colectivistas; se concentra en garantizar una serie de derechos sociales (educación, salud, seguridad social, vivienda), y reconoce que el llamado bien común exige una limitación en la libertad individual, incluso desde el punto de vista económico. El concepto de justicia social ${ }^{36}$, que toma en este momento su significado actual, define una visión de la sociedad no necesariamente progresista, sino que muchas veces presenta, junto a propuestas de reformas sociales, elementos de fuerte restricción a las libertades políticas y planteamientos próximos al conservadurismo.

Camús, que parece buscar una síntesis entre ambas posturas, asume por un lado que "el pobre no tiene derecho de reclamar el socorro que su triste situación exige" (1847: 13), pero igualmente reconoce que esta ayuda es "un deber sagrado", "tanto mas imperioso, cuanto mayores sean los obstáculos que se opongan á una proporcionada distribucion de la riqueza" (1847:13). En este sentido, insiste, la caridad privada resulta insuficiente y — citando De l'esprit des loix de Montesquieu- afirma que el gobierno "debe á todos los ciudadanos indistintamente una subsistencia asegurada, el alimento, un vestido conveniente y un género de vida que no sea contrario á la salud" 37 .

Es preciso, por tanto, encontrar una vía entre la caridad privada, la intervención de la administración del Estado en el socorro de los pobres, y la salvaguarda del principio de inviolabilidad de la propiedad privada. Hemos visto cómo Camús encuentra inspiración en teóricos católicos como Villeneuve-Bargemont y Ferdinand Esterno y en el filántropo y sociólogo barón de Gérando, pero también se acerca a políticos del Partido Moderado, aunque razonablemente progresistas, como José Posada Herrera, Javier de Burgos y, quizá, Francisco Cea Bermudez, todos ellos activos entre 1820 y 1840.

De los primeros, Camús toma la idea de la necesidad de actuación pública para prevenir el estallido social y de la necesaria redistribución de las riquezas a través de una regeneración moral que solo puede venir del cristianismo:

Le système anglais repose sur la concentration des capitaux, du commerce, des terres, de la industrie; sur la production indéfinie; sur la concurrence universelle; sur le remplacement du travail humain par les machines; sur la réduction des salaires; sur l'excitation perpétuelle des besoins physiques; sur la dégradation morale de l'homme.

Fondons, au contraire, le système français sur une juste et sage distribution des produits de l'industrie, sur l'équitable rémunération du travail, sur le développement de l'agriculture, sur une industrie appliquée aux produits du sol, sur la régénération religieuse de l'homme, et enfin sur le grand principe de la charité38.

36 Se atribuye al sacerdote jesuita Luigi Taparelli (1793-1862), inspirador de la encíclica Rerum novarum, la creación de esta expresión, que se difundió a partir de las revoluciones de 1848. Cf. A.. Biasini, Indagini sul concetto di "diritto" tra pensiero classico e moderno Diritto soggettivo, proprietà e autorità in Luigi Taparelli d'Azeglio, 2013, tesis doctoral dirigida por Paolo Pagani, consultada en línea el 22 de noviembre de 2016 en la página de la Università Ca Foscari Venezia. Scuola Dottorale d'Ateneo.

37 Cf. Montesquieu, Oeuvres complètes, Paris, Fermin Didot, 1738, p. 405: De l'esprit des loix, livre XXIII, ch. XXIX, Des hôpitaux.

38 A. Villeneuve-Bargemont, Économie politique chrétienne ou recherches sur la nature et les causes du pauperisme en France et en Europe et sur les moyens de le soulager et le prevenir. Tome 1, Paris, Paulin, 1834, p. 24. 
De los segundos, nuestro autor toma la idea del compromiso entre la tradición y el liberalismo, especialmente la necesidad de modernizar la administración pública para dar respuesta a las nuevas necesidades sociales que produce la transformación económica. Así, José Posada (1814-1885), catedrático de la Escuela especial de Administración (1843), ministro de Gobernación en 1858 y 1865, presidente del Ateneo de Madrid (1865-68), y autor de unos Estudios sobre la beneficencia (1845), plantea, desde el punto de vista administrativo, los medios por los que la sociedad puede atender a los desposeídos, ya sea con socorros a través de una "caridad legal", es decir, una ayuda en dinero a aquellos que no son capaces de trabajar, ya sea mediante la consecución de un puesto de trabajo para aquellos que están en situación de trabajar ${ }^{39}$.

Camús destaca la instrucción del 30 de noviembre de 1833 de Javier del Burgos de la que ya hemos hablado, y que contiene los principios morales por los que se debería regir la administración. Tanto uno como otro comparten una idea, con la cual parece concordar nuestro autor y que expresa citándola al final de su discurso:

Si el labrador robusto, el capitalista opulento, y el especulador activo necesitan del fabor y de la proteccion constante del gobierno para adelantar sus intereses y mejorar su condicion, mucho mas lo necesita el pobre jornalero á quien la enfermedad postra en el lecho del dolor; el anciano indigente á quien la edad niega el consuelo y los ausilios del trabajo; el niño recién nacido á quien las preocupaciones ó la crueldad de sus padres condenan á chupar los secos pechos de una nodriza mercenaria: el desventurado en fin á quien la ley confina en un encierro, mientras se confirman ó se desvanecen los indicios que le acusan de haberla infringido $(1847: 17-18)^{40}$.

En definitiva, la administración tiene la obligación moral de intervenir para paliar las carencias de los miembros de la sociedad más desfavorecidos y, además, es legítimo que lo haga destinando a ello recursos económicos que superen la beneficencia voluntaria. Eso no significa — se apresura a repetir nuestro autor- que las clases desfavorecidas estén en el derecho de "invocar los injustos beneficios de una ley agraria ni menos aspirar ver realizadas las utopias de los socialistas de todos los tiempos" (1847:18); la reforma, necesaria, no debe modificar lo más mínimo el orden social y el derecho sagrado sobre la propiedad.

Camús da respuesta negativa a dos de las reclamaciones más significativas del proletariado de España. En primer lugar, la repetida mención a la ley agraria, que hace resonar en nuestros oídos los discursos de Tiberio Graco contra los optimates o de Cicerón contra Catilina, no es únicamente un adorno retórico para un auditorio cultivado. Los procesos de desamortización que se sucedían desde el inicio del siglo — la desamortización de Mendizábal había tenido lugar entre 1836 y 1837, y la de Madoz se iba a producir poco después, entre 1854 y 1856 - no solo afectaban

39 J. Posada Herrera, Lecciones de administración. Estudios sobre la beneficencia pública, Madrid, Imprenta de la Sociedad de Operarios del mismo arte, 1845. p. 18-29. El texto lo reporta Gonzalo Capellán de Miguel, Enciclopedia del pauperismo, vol. II, Universidad de Castilla-La Mancha, 2007, pp. 39-46.

40 "Real Decreto disponiendo los Subdelegados y demás empleados de Fomento que ha de haber en las provincias, é instrucción que acompaña y deberán aquellos observar”. Decretos del Rey Nuestro Señor Don Fernando VII, y de la Reina su Augusta Esposa. Por don Josef María de Nieva. Colección legislativa de España: continuación de la colección de decretos, Volumen 18, p. 370. 
a las tierras de "manos muertas" propiedad de las órdenes religiosas y militares, sino también, y muy especialmente, a las tierras de propiedad comunal que habían significado el sustento secular de las pequeñas comunidades agrarias. La restitución de estas antiguas propiedades vecinales era una reclamación que estaba en boca del campesinado más pobre, en la medida en que eran capaces de hacerse oír, pero el Estado, que se había arrogado el derecho de subastar esas tierras, no se planteaba ahora desposeer de ellas a sus nuevos propietarios.

La segunda reclamación que deniega Camús tiene que ver con las exigencias del movimiento obrero, clasificadas como "utopías socialistas de todos los tiempos", expresión con la que nuestro autor engloba, de modo bastante displicente, las propuestas de mejoras sociales lanzadas por las diversas corrientes de socialismo premarxista que se habían difundido por Europa, especialmente en Francia, durante los dos decenios anteriores, y equiparándolas a otras obras de la literatura utópica de la Antigüedad y el Renacimiento rayanas con la literatura fantástica.

Admite, sin embargo que el Estado tiene la obligación de subvenir a las necesidades de los desfavorecidos, pero sin alterar la distribución de la propiedad ni de la riqueza. Camús no explica, en realidad, de qué modo se puede sufragar esta ayuda, aunque insiste que esta pretensión es "un derecho indisputable" de los desposeídos. La conclusión lógica parece ser, pues, la imposición de una tasa sobre las actividades económicas - y no sobre las propiedades inmuebles y los predios- que proporcione al Estado los medios para acudir a los necesitados. Esta distinción no carece de importancia, porque deja libre de cargas a los grandes propietarios y grava la especulación financiera, cuestión bien vista por el sector más tradicionalista, que la define como un fenómeno económico con efectos sociales disruptivos para el orden tradicional.

De hecho — si dejamos de lado las reivindicaciones que se alzaban desde las filas del proletariado - la imposición de tasas a la actividad económica para "suavizar los males de la desigualdad de fortunas" (1847: 18), era una propuesta que se formulaba en círculos católicos, considerados conservadores por la burguesía liberal, que defendían una visión orgánica de la sociedad concibiendo al Estado no solo como un instrumento para el desarrollo económico, sino también como un medio para el ejercicio de la caridad colectiva, más allá de las iniciativas individuales, necesariamente parciales. Esta es la posición, como hemos visto, de los autores que inspiran el discurso de Camús, especialmente de Gérando en Le visiteur du pauvre de 1824 y de Villeneuve-Bargemont en L'Économie politique chrétienne de 1834.

Nuestro autor se alinea, de este modo, no con el liberalismo económico estricto, sino con una corriente católica que, superando el tradicionalismo inmovilista, admite los progresos del desarrollo económico pero no reniega de la idea de una sociedad cohesionada por medio de la moral y de la religión.

Los principios de este grupo de pensadores católicos no se concretarán hasta 1891 en un documento oficial, la encíclica Rerum Novarum de León XIII, casi dos decenios después de la insurrección de la Comuna, pero Camús demuestra conocer desde el inicio a los principales inspiradores de esta corriente ideológica llamada, en Francia y en Alemania, a tener una importante repercusión en el naciente movimiento obrero e incluso en la política de Estado, con las reformas sociales del canciller Bismarck sugeridas por teóricos como Lorenz von Stein.

Camús ocupa así una posición que lo acerca a políticos como Cea Bermúdez o Javier de Burgos, partidarios, dentro de la política burguesa, de una via media entre 
el tradicionalismo y liberalismo que permita afrontar las transformaciones sociales producidas por el desarrollo del capitalismo con mayor armonía social, y que encuentran en la historia y en la religión la guía para adentrarse en un progreso que, a sus ojos, no carece de sombras.

Al contrario que en Francia, esta posición de compromiso no tuvo oportunidad de prosperar en España, donde las posiciones políticas estaban exacerbadas por las guerras civiles carlistas y donde el poder hacía gala de no atender a las reclamaciones de la clase obrera. En nuestro país, la doctrina social de la Iglesia se aplica con éxito desigual. El predominio de las corrientes más tradicionalistas del catolicismo - uno de cuyos más perceptibles resultados fueron la primera "cuestión universitaria" ${ }^{41}$ de 1867-1868 y el posterior Real Decreto y Circular de Orovio de 1875, que apartaba de sus cátedras a los profesores universitarios contrarios a aceptar la censura previa de los programas de sus asignaturas - tuvo como resultado un fuerte anticlericalismo de los intelectuales progresistas. La falta de compromiso ideológico entre los progresistas moderados y el tradicionalismo, dejó la mayor parte de las iniciativas sociales en el campo del movimiento obrero, y solo fueron asumidas por el Estado parcial y tardíamente, provocando un profundo malestar social que alentaba con fuerza la amenaza de revolución social.

Quizá el último intento de llevar a cabo una política de estas características en nuestro país corresponde, salvando las distancias, a la Unión Patriótica, formada en 1924, durante la dictadura de Primo de Rivera, en el seno del catolicismo político. José María Pemán, uno de sus ideólogos, esforzándose por distinguirlo el fascismo, afirmaba que representaba el pensamiento "tradicional socialcristiano", al mismo tiempo que renegaba del sufragio universal considerándolo "un gran error"

El pensamiento social de Camús, puesto en perspectiva, nos aparece como una de las primeras manifestaciones en nuestro país de una corriente social cristiana moderada, importantísima para entender la deriva autoritaria y corporativa de los Estados burgueses en el momento de la agudización de los conflictos sociales en el periodo de entreguerras. Camús se desmarca tanto del carlismo como de la visión social del liberalismo económico, pero su propuesta, en este discurso sobre el pauperismo, es poco definida y contemporizadora. En todo caso, nuestro autor conoce los textos fundacionales de esta corriente ideológica, pero renuncia a analizar a fondo la realidad social del momento. Su lectura de la historia del mundo antiguo y lo que parece ser una visión corporativista de la sociedad basada en el catolicismo, lo llevan percibir la transformación económica como una pérdida de armonía social. No obstante, los remedios que propone - al menos en estas pocas páginas de que disponemos - no implican la restauración de un modelo social que da por acabado, ni tampoco la reconstrucción de la sociedad sobre nuevas bases. El temor a los cambios inclina a Camús hacia soluciones paliativas, basadas en la caridad y en la buena voluntad, con la plena conciencia de que son imperfectas y condenadas a la ineficacia.

41 Camús firmó la petición elevada a Narváez para la reposición en sus cátedras de los profesores que perdieron sus cátedras durante la "primer cuestión universitaria" que provocó la destitución de Castelar y la dimisión de Salmerón y Morayta y que concluyó con los acontecimientos de la Noche de san Daniel. Cf. F. García Jurado, op. cit. p. 11, y Capellán de Miguel, "Política educativa bajo los gobiernos de Cánovas y Sagasta: Propuestas para una interpretación", p. 127.

42 G. García Queipo de Llano, El reinado de Alfonso XIII. La modernización fallida. Madrid, Historia 16, 1997, p. 104. 
En palabras de Francisco García Jurado, uno de los principales estudiosos de esta figura, Camús, "más que un hombre de su tiempo, fue una víctima de él"43; las soluciones de compromiso por las que su talante moderado se inclinaba, su independencia de las grandes corrientes políticas del momento, y una cierta tendencia a rechazar protagonismo académico y social impidieron que su figura alcanzase la relevancia y la posteridad de las que su ingenio, sus luces y su magisterio le hicieron merecedor.

43 F. García Jurado, op. cit. p. 63. 